\title{
Using online technologies to support problem based learning: Learners' responses and perceptions
}

\author{
Ron Oliver and Arshad Omari \\ Edith Cowan University
}

This paper reports a study in which a form of on-line problem-based learning was employed with a group of on-campus students in an undergraduate university course. The paper explores the practical issues associated with teaching and learning in this fashion and describes the responses and perceptions of the learners. In the main, the students responded very positively to the changed learning environment despite the fact that it caused them to spend more time in these courses doing different things to which they were accustomed. In particular the students' perceived that the various problem-based activities contributed substantially to their learning and enjoyment in the course. The results do, however, suggest some caution is necessary in the use of this approach. While the environment seems readily transferable to flexible and open learning settings, the students frequently indicated that they valued the input of the teacher and saw this component as a valuable part of teaching and learning. The results suggest the need to remember the important place of the teacher in any learning process and the need to ensure students have adequate access to, and lines of, communication with their teachers.

\section{Introduction}

An emerging trend in education worldwide is a movement of the focus from that of teaching to that of learning (eg. Ramsden, 1992; Bates, 1995). Examples of this trend are evident in many ways. For example, the move in contemporary learning theories away from instructivist paradigms to those which more readily describe and explain learning (eg. Jonassen, 1991). Increasingly we are seeing a move from content centred curricula to outcomes based modes of curriculum design and with these moves has come an increased use of technology as an aid to learning and the development and increased use of student centred learning environments. 
Today, the forms of activity that are frequently suggested as necessary and sufficient conditions for effective university learning are those with high degrees of interactivity and engagement and which provide a motivating environment based on a well structured knowledge base (eg. Chalmers \& Fuller, 1995). These activities and conditions incorporate such tasks as the solution of real world problems, students working in collaborative and cooperative teams, problem negotiation and solving, and free and open communication among learners and with their teacher. Such activities are seen as supporting the development of higher order thinking and learning and at the same time, developing students' learning strategies. But in instances where universities are looking to economies of scale in the forms of delivery employed, the capacity of, and opportunities for, staff to employ such teaching and learning strategies, are becoming limited and less viable.

Increasingly educators are looking to learning technologies as a possible solution to the problems associated with delivering quality programs efficiently to large numbers of students (eg. Freeman, 1998). However in the process of adopting technologies, educators have often not looked to fully exploit their potential and most learning technologies in the past have been directed towards the presentation of content rather than the answering of questions or the opportunity for discussion and reflection.

Many writers are now providing ideas and strategies to guide and support learning in universities. Mayes and Neilson (1995) argue that the massification of higher education has increased the need to support individual learners through learning dialogues. Laurillard (1993) describes teaching as mediating learning and suggests the importance of a conversational framework in media supported learning which provides for discursive, adaptive, interactive and reflective forms of communication in academic dialogues. The WWW and online applications offer considerable prospect for the support of these forms of communication and it is this use of technology which forms the focus of this paper.

\section{Developing new models for university learning}

Contemporary educational thinking is leading educators to make a number of changes to conventional forms of university teaching. These changes are occurring to both the way in which courses are delivered and the content of the courses themselves. For example, there is currently a tendency among university teachers using the World Wide Web (WWW) for teaching and learning to simply reformat on campus course materials and learning strategies into an online form (Parker, 1997). Such an approach tends to significantly underutilise this technology and limits 
many of the learning opportunities that are afforded. Many new strategies are now being proposed for designing effective WWW based learning environments (eg. Collis, 1997) and common elements in the suggested design strategies are engaging and interactive learning activities based on collaborative activities.

There are number of different frameworks which have been used to successfully describe the learning advantages which are frequently reported as emerging from collaborative learning. For example, the reward structures inherent in collaborative environments have been found to have a positive effects on student motivation (Slavin, 1977). When students are able to participate in active learning activities, they find the learning more pleasurable and satisfying than non participative events (Fry \& Coe, 1980). In such settings, student learning is enhanced by both individual and joint efforts within the groups, and the environments frequently lead to higher levels of task related interaction and behaviour (eg. Johnson, Johnson \& Stanne, 1986).

Computers and learning technologies provide a natural stimulus for collaborative learning by increasing opportunities for social interactions and cooperation (eg. Hoyles, Healy \& Pozzi, 1992). Hoyles, Healy \& Pozzi (1994) report quite powerful interactions between students involved in computer based tasks where the collaboration was seen to lead to higher order thinking, hypothesis formation and reflection. Light (1993) reports on a review of studies which investigated the potential of computers to enhance group work and provides quite convincing evidence of the value of groupwork and collaboration and its positive impact on productive learner dialogue, interchange of ideas and negotiation of solutions.

While the use of collaborative approaches to learning sees a change to the way courses can be delivered, questions about the transferability and relevance of the course content is also causing educators to reflect on the structure of many university courses. Whereas previously course content has been highly structured and specific, writers are now urging designers to consider more open forms of content for their courses and an emphasis on the process of learning more than the product (eg. McManus, 1995; Duschatel, 1997).

One strategy that holds considerable potential for supporting more open forms of teaching and learning and involving collaborative learning activities is problem based learning. Problem based learning involves 
learning through goal directed activity situated in circumstances which are authentic in terms of the intended application of the learnt knowledge (Elen \& Clarebout, 1998).

\section{Problem based learning}

Problem based learning is a curriculum approach which helps the learner frame experience as a series of problems to be solved and where the process of learning unfolds through the application of knowledge and skills to the solution of real world problems, often in the contexts of real practice (Bligh, 1995). It is a form of situated learning, learning through goal directed activity situated in circumstances which are authentic in terms of the intended application of the learnt knowledge. Situated learning is based on the premise that the nature of the situation and the circumstances in which knowledge is learned are both influential in determining the likely prospect of subsequent redeployment to other situations and settings (Brown, Collins \& Duguid, 1986).

Situated learning draws on the relationship between construction of knowledge and the circumstances of its acquisition and integrates constructivist and socio cultural perspectives of learning. Such thinking is drawn from cognitive learning theory which sees learning not so much as a function of behavioural responses but more as a function of what learners know and how they acquired that knowledge. Contemporary learning theories such as constructivism and socio cultural theory present a view which highlight the social and cultural influences in knowledge acquisition and learning (eg. Billett, 1996).

A common problem with much of the instructional design associated with traditional university teaching has been the decontextualising of knowledge and learning. Jonassen (1991) argues that "the most effective learning contexts are those which are problem or case based and activity oriented, that immerse the learner in the situation requiring him or her to acquire skills or knowledge in order to solve the problem or manipulate the solution" (p. 36). Problem based learning and the use of authentic tasks have become an alternative to more content oriented approaches to education. Problem based learning builds on experiences and empirical findings that students learn more from a problem oriented task than from a fact oriented one. At the same time problem based learning environments are frequently reported to increase student motivation, to develop their critical thinking skills and deepen their understanding of significant content (Sage \& Torp, 1997). 
Promoting learning through problem based activities requires learners to solve authentic problems, problems which reflect the way in which the learned information will be used outside classroom settings (eg. Herrington \& Oliver, 1997). Authentic problems tend to be ill structured with multiple solutions. Students need to use a multitude of perspectives in the problem solution and many solutions exist for the problem. This form of learning, it is argued, can provide better forms of learning transfer between the university setting and the workplace as well as enhancing students' abilities to continue to learn beyond the classroom setting (Herrington \& Oliver, 1998). It is this potential which often motivates the use of problem based learning and exploration of the factors which influence its success.

Problem based learning has become very popular in university programs across a range of courses including business, education and science. In medicine and biology, for example, learners are often required to deal with large amounts of information in ways which reflect the forms of practice for which they are training. Whereas in traditional courses, students would have been exposed to the information in such activities as lectures and workshops, in problem based environments students are required to use the information in meaningful ways as they will be required when they graduate (eg Prawat, 1993; Fenwick \& Parsons, 1998). Such forms of learning draw heavily on communication and collaboration among learners. The context in which the activity takes place has a strong influence on the forms and types of learning achieved (Vernon, 1995).

\section{The learning environment}

The development of effective problem based learning involves the successful implementation of a number of critical elements. In a technology supported problem based learning environment the main elements which influence outcomes are the problem selection, the technological environment and the forms of learner support that are provided (Elen \& Clarebout, 1998). Creating appropriate tasks for the learners influences to a large degree what will be learned. Hence a critical aspect of student learning and achievement is the selection of the problem itself. Elen \& Clarebout (1998) argue the need for three interdependent aspects to be considered in problem selection: the amount of structure in the problem; the learning goals being sought; and the characteristics of the intended learning audience. The selection of the task influences significantly the forms of problem solving engaged. For example, well 
structured problems are appropriate for knowledge and skill acquisition. Ill structured more suited to conceptual development and problem solving development.

Problem based learning can be supported well through various instructional technologies by virtue of the information access and cognitive support which they can provide. For example, use of the WWW provides access to a raft of information and resources which can be used in the problem solution. The conferencing capabilities of the WWW also add considerably to its capacity to support problem based learning. Learners using electronic conferencing can establish a sense of community among themselves and teachers can become more accessible to learners. The same applications can return disadvantages in some ways. Increased electronic communication can limit the capacity of teachers to deal with students. In electronic conferencing, the content of the discussion can be poor and not all topics relevant to the courseware may be discussed. A number of researchers are now exploring ways to support technology based teaching and learning and in particular to support computer conferencing and asynchronous communication (eg. Masterton,1998).

\section{Developing a problem based learning curriculum}

Given the various factors which need to be addressed in developing effective problem based learning environments, it is not immediately obvious which are the best combinations and which is the best blend of problem type, technological environment and support mechanism. It is clear that the choices among these have the potential to impact on outcomes and it was the intention of this project to explore relationships between these various factors and their impact on student activity and learning.

The encouragement to explore and experiment with a problem based learning setting emerged from problems identified by the principal researcher in his teaching programs. In previous classroom settings, students attended lectures where the course material was presented and discussed and where workshop activities were used to provide meaningful settings for students to develop their knowledge and understanding of the course content. The workshop activities included group discussions, role plays, debates and other similar forms of interactive learning. Several consistent problems became evident in these learning settings. Firstly, presentation of the material in the form of a lecture or teacher directed activity was limiting and ineffective from a 
learning perspective. Secondly, the fact that students' first exposure to the material was typically in the lecture setting limited their ability to work meaningfully with the information in the workshops. The students had insufficient time to make meaning or to develop their understanding of the material that was being covered.

A project was therefore devised which saw the development of a problem based setting to replace the conventional delivery of 2 courses and the implementation of these using WWW technologies to support information access and collaboration. The implementation was accompanied by an action research project by it was intended to explore student learning with the view to developing an understanding of the various factors which influenced the effectiveness of the changed learning environments.

\section{Research aims}

The intention of this project was therefore to explore the potential of online and WWW based technologies to support problem based learning through an application in several university courses. In particular the project sought to explore:

- Possible implementation strategies for online problem based learning environments;

- the strategies and processes used by the students in dealing with the problem based settings;

- students' responses to the alternative form of learning associated with problem based learning;

- students' perceptions of the relative learning impact of the various student centred activities involved in the problem based environment; and

- issues arising from the use of problem based learning in an online environment.

\section{The learning activity}

The planning for the problem based learning settings involved developing an alternative format to the standard weekly lecture/ workshop style of teaching which saw the delivery of the course content being moved from being teacher centred to becoming student centred. The plan for the new environment evolved to being based on a weekly activity where students would work in collaborative groups of 4 or 5 to develop a solution to a problem. The weekly problem was planned to require students to explore 
and delve into their course content for the week and to meaningfully apply that content in a way that reflected an authentic or realistic application of the knowledge.

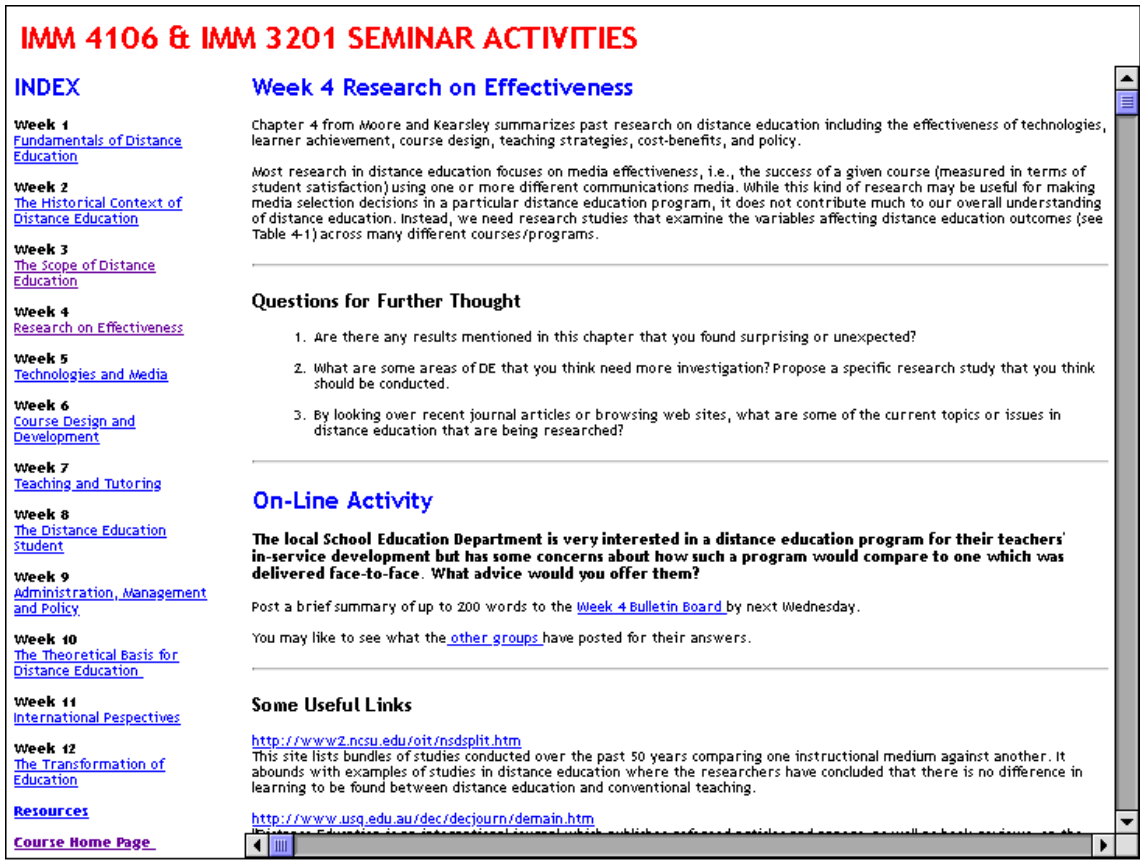

Figure 1: The online problem based environment

The development of problem based learning activities provided a possible solution to several dilemmas. In the first instance the problem setting appeared to provide a meaningful way for the learners to explore the material themselves and remove the need for the lecture of teacher directed activity. In the second instance, solving the problem ahead of class would enable students to come to class already familiar with the content and for the class activities to move on from this advanced standpoint.

The problem based setting was planned for 2 discrete courses that ran concurrently throughout a semester. Both courses were similar in many respects and provided an ideal testing ground for the alternative learning format. Both courses: 
- involved relatively small cohorts of students;

- dealt with topics and content that lent itself to development in this form;

- had previously been taught through teacher directed activities;

- were based around a strong textbook that provided the basic content for the topics being learned.

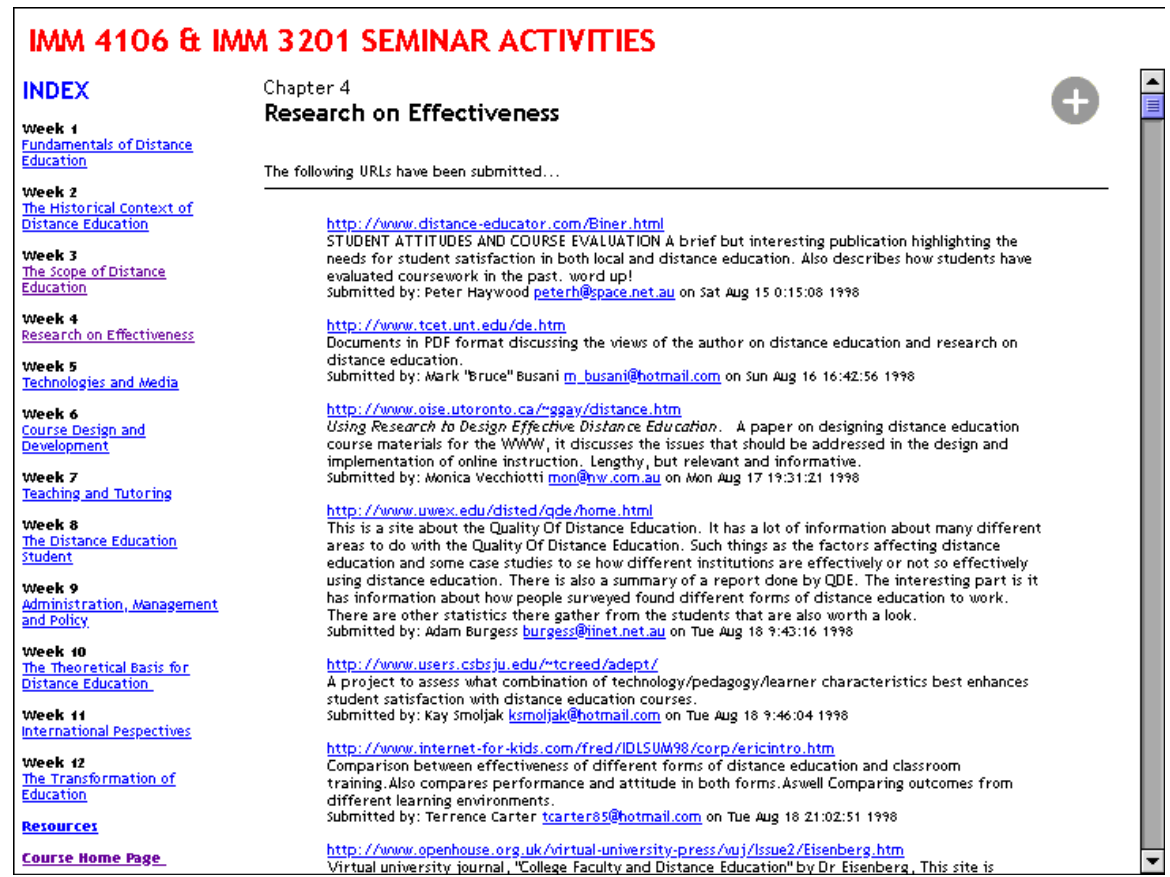

Figure 2: The problem solutions public bulletin board

In planning the problem based setting for each course, the WWW was used as a means to present the weekly problems and to provide access to multiple sources of information for the problem solution (Figure 1.). The conferencing capabilities of the WWW were used to enable students to communicate and collaborate in their groups and to post their solution ahead of class to a public bulletin board for others to view (Figure 2.). Another component of the WWW support was that of a bulletin board to which students could post relevant URLs for others in the class to use in their research and inquiry (Figure 3.). 
The weekly problems were created in a fashion that made them ill structured and open providing scope for a variety of solutions and responses. The problems provided students with the opportunity to seek information from sources beyond the immediate setting, from reference books, WWW sites and even informed peers. For example, in the course on Data Communications in the week dealing with the topic of digital communications, the problem posed was:

Unencrypted digital data sent through the Internet can be intercepted and accessed by unauthorised people. How might a person make sense of a data stream on an intercepted T1 line?

Problem selection was a very difficult process and it was evident that choosing the right form of problem was very important in terms of enhancing learning and understanding. In response to the question above, a typical answer was:

\begin{abstract}
Data sent across a T1 line is encapsulated in frames and sent using one of two main framing structures. The first is a D4 basic superframe which consists of 12 consecutive frames. The second is an ESF (extended superframe) which consists of 24 consecutive frames. To further complicate things each frame contains data for each of the 24 separate channels a T1 line supports. We will assume that a D4 framing structure is being used for this example. Our spy would therefore need to know what framing structure was being used and how each frame organises the data for each channel it carries so that he or she can separate the data for eachchannel, otherwise the resulting message would be a mixture of all 24 (think of it as trying to listen to 24 separate conversations at once). A standard T1 frame consists of 193 bits. There are 24 channels in each frame (each consisting of 8 bits of data) plus 1 framing bit used for synchronisation forming a total of 193 bits per frame. Therefore we have a D4 superframe consisting of 12 consecutive frames each of which contain 24 separate channels with 8 bits of data in each, and a single framing bit for each frame (ie 12 in total). The 12 framing bits are arranged in a special pattern. By looking for this specific pattern in every 193 bits (which is where the framing bit occurs) the spy can identify individual frames in the D4 superframe and then identify which 8 bits are for each of the 24 channels.
\end{abstract}

The creation of the response encouraged learners to think about digital data transmission, to investigate how it is carried out and to understand the processes. The use of groups provided a scaffold for learners for whom this was a difficult task. While seeking information to help in the development of a problem solution, students were also required to answer a number of focus questions which were intended to direct their reading and to cause them to explore fully the material associated with the weekly topic. It was possible in some of the problems for students to explore 
information sources that were away from the planned topic and the use of the focus questions was seen as a means to ensure students had been exposed to those parts of the course content that were considered important and necessary in the overall context of the course.

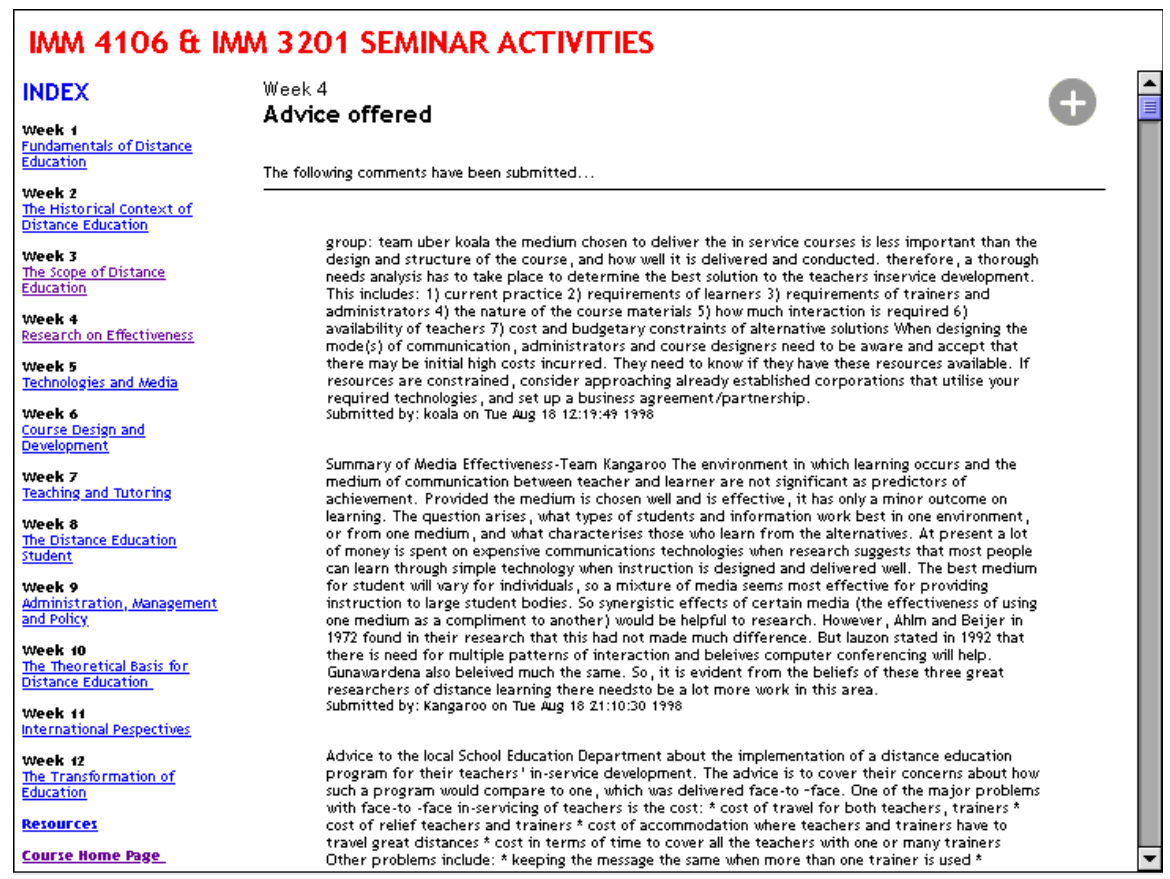

Figure 3: The public bulletin board by which learners could share relevant resources

Class time each week was spent in a consistent fashion. During the workshop, the teacher printed hard copies of the posted problem solutions and distributed them to the class members. A class discussion then followed during which time the various solutions were discussed and analysed and the strengths and weaknesses of each noted. At the end of the discussion, students were asked to assess each solution and to give a ranking for each. The combined results of the rankings became a mark which was given to each group and which cumulated throughout the semester to provide an assessment for the students of their problem solving activities.

The two classes in the study differed in several respects and provided some interesting contrasts in exploring the effectiveness of the problem 
based learning environment. Class A had 22 students who were mostly studying full time and attended classes during the day. The unit was a core unit in an undergraduate degree program but one which not all felt was totally relevant to their needs and interests. The majority of the students were recent school leavers studying full time and most knew each other from previous classes and studies. Class B had 35 students and was studied after hours. This was also a core unit in an undergraduate degree program but the cohort was not well known to each other since there were many $(40 \%)$ part time students in the group. A majority of the students were mature age students and few students knew each other from previous studies or classes.

\section{Outcomes}

During the implementation of these courses, an action research project was carried out which was intended to explore the ways students dealt with the changed learning environment, their impressions of the value of the various learning activities and to provide feedback to enable the success of the environment to be judged. Data was gathered from the students at several stages in the course from questionnaires and interviews. The following discussion describes the findings and discusses the aspects which were found to influence learning outcomes and students' satisfaction with the course.

\section{Student activity and learning strategies}

Questionnaires and interviews were used at the end of the course to explore the ways in which the students dealt with the various requirements of the course in terms of their independent learning and problem solving activities. When questioned about the amount of time spent on preparing for the weekly class activities, it became evident that there were large variations among the learners. Table 1 . shows the average time students judged that they spent each week in the various activities ahead of the classroom sessions.

\begin{tabular}{|l|ccc|ccc|}
\hline Learning task & \multicolumn{3}{|c|}{ Class A } & \multicolumn{3}{c|}{ Class B } \\
& Min & Max & Av & Min & Max & Av \\
\hline Answering the focus questions & 0.50 & 2.00 & 1.25 & 0.75 & 1.50 & 1.00 \\
Solving the weekly problem & 0.25 & 2.00 & 1.15 & 0.20 & 2.50 & 1.25 \\
Using the WWW for & 0.50 & 3.00 & 1.75 & 0.50 & 1.50 & 0.80 \\
information & & & & & & \\
\hline
\end{tabular}

Table 1: Students' judgements of average weekly time (hours) spent in learning activities ahead of class 
The feedback from the students provided some interesting insights into the ways in which they dealt with the changed learning environment. Students were generally very positive about the learning benefits gained by being required to spend time preparing for the weekly class. The vast majority recognised the value of taking a more active role in dealing with the course content and expressed favourable opinions on this aspect of the environment. There were large discrepancies in the amounts of time spent by students in each class in preparation for the class activities. The use of a peer assessment strategy created a strong incentive for all students to prepare for classes and all expressed a degree of comfort and satisfaction with this requirement.

The focus questions activity was not cognitively demanding in that it required students to use existing materials to answer mainly objective questions about the course content. The purpose of these questions was to ensure that all students were exposed to and dealt with, the complete curriculum. One of the difficulties with a problem based setting is not being able to guarantee full coverage of a planned curriculum (eg. Fenwick \& Parsons, 1995) and this activity was designed in part in response to this.

Students claimed to have spent similar amounts of time in the problem solving activities as in the focus questions. Once again large variations existed between the students with some spending 15 minutes per week and others spending 2 hours per week on these activities. The discrepancy in time spent on the problem solving came about as a consequence of the role various students played in their groups. It was apparent that different groups developed different strategies for the problem solving process. The most common strategy was for all members in a group to seek information and to propose a solution and to use email to send their results to a person designated as leader for the week. The leader then consolidated the responses into a coherent form and passed this back to the group for final comment before the leader posted it to the bulletin board. With this strategy, the role of leader was shared around the group members and each leading the activity at least twice throughout the course.

In some other groups, one student took the lead role throughout the semester. This happened in several groups where more able students completed the synthesis task each week rather than sharing it around. The reasoning for this was to provide the group with the best possible solution while providing everyone with an opportunity to play some part in the 
solution process. It was evident from the interviews with students that students assumed roles in the problem solving process commensurate with their enthusiasm and interest in learning. Those students who were looking to gain the maximum from the course undertook the most time consuming tasks. Others seeking to pass the unit tended to rely on their peers to do the bulk of the work and to make a minimal contribution. Students were not advised as to how they were to complete the problem solution and the variations within the groups reflected the dynamics and processes associated with providing enhanced levels of learner control.

In the interviews students who made the bigger contributions were asked about their feelings towards group members who contributed minimally to the problem solving activity. In the main, the lead students were not concerned with the minimal roles played by their peers. They commented that the various roles enabled everyone in the group to follow their own motivations and interests and this meant that lead students did more work but clearly they felt that this helped them to learn more at the same time.

\section{The impact of the learning activities}

The students were asked to provide feedback on their perceptions of the impact of the various learning activities on their learning. They were asked to indicate their perceptions using a 5 point Likert scale: no influence at all; a little influence, a reasonable influence, a substantial influence; and a huge influence. Their responses were coded with the values $1 . .5$ and averaged to provide a relative measure. The average score and a ranking for each learning activity is shown in Table 2.

\begin{tabular}{|l|cc|cc|}
\hline \multirow{2}{*}{ Learning task } & \multicolumn{2}{|c|}{ Class A } & \multicolumn{2}{c|}{ Class B } \\
& Value & Rank & Value & Rank \\
\hline reading given WWW sites & 3.31 & 5 & 3.79 & 2 \\
problem solving & 3.94 & 2 & 3.61 & 3 \\
class discussions & 4.31 & 1 & 4.00 & 1 \\
answering focus questions & 3.64 & 3 & 3.46 & 4 \\
assessing each others' solutions & 3.63 & 4 & 3.32 & 6 \\
finding new WWW sites & 2.69 & 6 & 3.39 & 5 \\
\hline
\end{tabular}

Table 2: Students' perceptions of the relative impact of the various activities on their learning 
In analysing this data, it is important to consider the meaning carried by the different scores in this table. Scores greater than 4 indicate a learning activity which students rated on average as providing more than a substantial influence. A score between 3 and 4 shows a learning activity whose influence was judged on average to be between reasonable and substantial. An average score between 2 and 3 represents a learning activity judged to have had a little, but not substantial, influence.

The learning tasks which students felt had the greatest impact differed slightly between classes. In both instances the class discussions and problem solving activities rated highly while finding new WWW sites and assessing each other's solutions rated as having the least impact.. Although there was a discrepancy in the ranking of the various activities between the classes, overall the scores indicated that both groups found the various learning activities of value except in relation to Class A and the WWW activities. It is interesting to try to explore reasons for this difference. Students in Class A rated reading given WWW sites and finding new WWW sites as the least valuable learning activities. Class A was provided with large lists of URLs in the course home page as extra resources while Class B had fewer but more select lists. It appeared that students in Class A may have experienced a degree of information overload caused by the provision of long lists of URLs for their inquiry and over the period of a semester became disenchanted with the task of reading and exploring these lists.

\section{Class characteristics}

One of the important issues in online teaching and learning is student motivation and we were interested in this study to explore the factors which contributed to students' motivation and enjoyment of learning in this setting. Table 3. shows students' responses to questions seeking their perception of the influence of various class characteristics on their level of enjoyment in the course. Judging by the numeric values of students' responses, all characteristics were considered to have contributed substantially to students' levels of enjoyment.

We were interested in exploring the degree to which the online activities stimulated enjoyment and to see whether these factors might be stronger than those associated with the face to face delivery. In the list below, it is possible to see 3 characteristics associated with face to face teaching and 3 associated with learning online. The URL competition was a weekly event in which the best student URL was recognised and acknowledged as 
accorded the title "chocolate site of the week", an event that earned the student a chocolate and the site, a chocolate graphic.

Interestingly, in both classes, those aspects associated with face to face teaching were considered to have the greatest impact on motivation and enjoyment. In both classes, the teacher was considered to be the major determinant of enjoyment while class discussions and the informal class atmosphere also appeared as strong contributors to enjoyment. The factors which contributed least to enjoyment were the groupwork, the URL competition and the course content, those factors associated with online learning. This suggests a need for developers of online environments to remain alert to the motivational needs of their remote learners.

\begin{tabular}{|l|cc|cc|}
\hline \multirow{2}{*}{ Class characteristic } & \multicolumn{2}{|c|}{ Class A } & \multicolumn{2}{c|}{ Class B } \\
& Value & Rank & Value & Rank \\
\hline groupwork & 3.75 & 4 & 3.54 & 6 \\
the content of the course & 3.56 & 5 & 3.82 & 4 \\
URL competition & 2.81 & 6 & 3.57 & 5 \\
class discussions & 4.47 & 2 & 3.89 & 3 \\
informal atmosphere & 4.38 & 3 & 4.36 & 2 \\
the teacher & 4.69 & 1 & 4.68 & 1 \\
\hline
\end{tabular}

Table 3: Students' perceptions of the impact of the various class characteristics on their enjoyment

\section{Supports for learning}

The problem based courses involved a number of procedures and routines which are not always found in traditional classrooms but which can function effectively in online environments. Students were asked to consider the degree to which these activities were able to support their learning and their feedback is shown in Table 3. In all instances, the scores were above 3 and these values show that students generally saw all the listed activities as providing reasonable to strong levels of support for their learning.

It is difficult to pick patterns in these responses although the peer assessment activities ranked low in both instances while the weekly assessment tasks ranked very high. The weekly assessment tasks required students to prepare for class by completing a series of focus questions and 
posting a problem solution. In the other courses taken by these students, there is no preparation component and the students indicated by these responses that they saw this aspect of this course as a strong contributor and support for their learning.

The peer assessment activity involved students assessing the problem solutions of their peers and providing grades for these. Even though it ranked as providing least support for learning, the average values in both classes suggested that students still saw it as a useful support activity.

Some interesting discrepancies are evident in Table 4. In class A, students generally rated using the WWW as providing the least support while in Class B, this activity was considered to be the most supportive of learning. It would appear that this discrepancy may have been caused in part by the way in which the course notes provided for Class A contained large numbers of URLs and it became quite daunting for the learners to be faced with large numbers of www sites to explore not knowing what would be missed if sites were not explored and then finding only minimal amounts of useful information in some sites despite taking considerable time in locating them.

\begin{tabular}{|l|cc|cc|}
\hline Learning Task & \multicolumn{2}{|c|}{ Class A } & \multicolumn{2}{c|}{ Class B } \\
& Value & Rank & Value & Rank \\
\hline Peer assessment & 3.25 & 5 & 3.46 & 6 \\
Working in groups & 3.94 & 2 & 3.57 & 5 \\
Using the WWW for information & 3.20 & 6 & 4.14 & 1 \\
Using email to support groupwork & 3.56 & 4 & 3.64 & 4 \\
Preparation before class & 3.81 & 3 & 3.75 & 3 \\
Weekly assessment tasks & 4.13 & 1 & 3.89 & 2 \\
\hline
\end{tabular}

Table 4: Students' perceptions of the level of learning support provided by various learning tasks.

\section{Personal skills development}

The use of a problem solving strategy as the basis for teaching and learning in a course appears to provide considerable scope for developing students' personal skills such as information literacy, metacognition and self regulation these all being part of the arsenal of skills needed for lifelong learning. Students were asked to indicate how successful they felt the course was in developing such skills and Table 5. shows their responses to these questions. 
Once again, the responses of the students suggest that they saw their courses as contributing reasonably to their development in all areas. The responses from the students in Class A were generally less favourable than those from Class B and tended to show reasonable levels of satisfaction but no real highs or lows. In Class B the same pattern of response was evident , but with more positive views overall. In fact looking at Class B, where the average response was slightly less than 4 , it is evident that these students saw the course and its innovative design as contributing strongly to all forms of personal development described in the table.

General observations of overall satisfaction among the learners suggested that the students in Class A were generally less interested in their course than those in Class B. Both courses were core units but some students in Class A questioned the direct relevance of the material to their intended careers and as a consequence overall responses tended to be less positive than their counterparts in Class B.

\begin{tabular}{|l|ll|ll|}
\hline Learning Task & \multicolumn{2}{|c|}{ Class A } & \multicolumn{2}{c|}{ Class B } \\
\hline Using WWW for information & 3.25 & 5 & 3.93 & 2 \\
Stimulating interest in the area & 3.56 & 1 & 3.68 & 6 \\
directing your own learning & 3.44 & 3 & 3.82 & 4 \\
finding relevant information & 3.31 & 4 & 3.79 & 5 \\
being a discerning WWW user & 3.19 & 6 & 3.89 & 3 \\
maintaining current knowledge & 3.50 & 2 & 4.11 & 1 \\
\hline
\end{tabular}

Table 5: Students' perceptions of the impact of the unit on developing personal skills

\section{Discussion}

The study provided some valuable insights into the ways in which problem based learning environments can be created and sustained using online technologies. Our experiences in this setting revealed some important issues which carry the prospect of impacting significantly on student participation in problem based learning and subsequent learning outcomes. The first of these is perhaps one of the more important issues and that is the creation of the problems to be solved.

\section{Selection of the problem}

The problem selection proved to be perhaps the most challenging and most influential component of the learning activity. In developing the 
problems on a weekly basis, we had to contend with the need to create a relevant inquiry activity which reflected how the learned information might be used in settings beyond the classroom. At the same time we needed to create a problem which was open ended enough to require collaborative and creative problem solving but not too ill structured to cause students to digress too far from the intended learning outcome. In many instances we saw considerable potential for improving upon our problems and intend to pursue this in future work.

\section{Motivating activity}

Another issue which emerged in the study was that of providing a means to encourage and induce students to participate in the problem solving activity. For many the activity was cognitively demanding and challenging and this tended to lessen the enthusiasm of some for participating. In our setting, we used the inducement of continuous assessment as a strategy to encourage participation however the use of collaborative groups in the problem solving process enabled students to choose the extent of their participation and we found large discrepancies in efforts among the students.

\section{Peer assessment}

The use of peer assessment activities was not an essential component for the problem based learning environment but appeared to provide a means to motivate and encourage students' critical thinking and involvement in synthesising the various solutions. We have come away from the study with mixed feelings on whether this was a strong contributor to the learning outcomes. Some students expressed concern that the process could be influenced by rivalries and competition while others found the experience valuable and meaningful. The use of peer assessment holds strong prospects for building students' critical thinking skills and capacities to reflect and the problem solving activities provide a very useful context for development of these skills. Once again, this is an area we intend to pursue further in subsequent studies of these learning environments.

\section{Summary and conclusions}

The findings from this initial exploration with a WWW supported problem based learning environment have been very positive and have provided encouragement to continue our explorations. In the main, the students responded very positively to the changed learning environment despite the fact that it caused them to spend more time in these courses doing 
different things to which they were accustomed. In particular we were pleased with the students' perceptions that the various problem based activities did contribute substantially to their learning and their perceptions that the changed environment was enjoyable and stimulating.

But the results do provide information to cause reflection on our part in terms of students' perceptions of the contribution of face to face teaching components on their learning. While the environment is readily transferable to distance education and open learning settings, we were continually reminded by the students that they valued the input of the teacher and saw this component as a valuable part of teaching and learning. The caution we have learned from this is the need to remember the important place of the teacher in the process and to ensure that in future developments, students still have adequate access and lines of communications with their teachers.

We have been able to convince some of our colleagues of the value of this form of teaching and learning and are looking forward in the future to further developing the infrastructure and strategies associated with this application of problem based learning to create more flexible and effective forms for other disciplines and subject areas. We have come away convinced that the method provides a sound alternative to conventional delivery practices and are keen to further explore opportunities with future classes.

\section{References}

Bates, A. (1995). Technology, open learning and distance education. New York: Routledge.

Billett, S. (1996). Situated learning: Bridging sociocultural and cognitive theorising. Learning and Instruction, 6(3), 263-280.

Bligh, J. (1995). Problem-based learning in medicine: an introduction. Post-Graduate Medial Journal, 71(8), 323-326.

Brown, J., Collins, A. \& Duguid, P. (1989).. Situated cognition and the culture of learning. Educational Researcher, 18(1), 32-42.

Chalmers, D. \& Fuller, R. (1995). Teaching for learning at university: Theory and practice. Perth: Edith Cowan University.

Collis, B. (1997). Pedagogical reengineering: A pedagogical approach to course enrichment and redesign with the WWW. Educational Technology Review, 8, 1115. 
Duchastel, P. (1997). A motivational framework for web-based instruction. In (B. Khan, (Ed.), Web-based Instruction. New Jersey: Englewood Cliffs.

Elen, J. \& Clarebout, G. (1998). Problem-based learning in technologically rich environments: The issue of teacher support.. In Chan, T., Collins, A. \& Lin, J. (Eds). Global Education on the Net: Proceedings of the 6th International Conference on Computers in Education. China Higher Education Press Beijing and Springer Verlag, Heidelberg. (pp 473-480).

Fenwick, T., \& Parsons, J. (1998). Boldly solving the world: a critical analysis of problem-based learning as a method of professional education. Studies-in-theEducation-of-Adults, 30(1), 53-66.

Freeman, M. (1997). Flexibility in access, interaction and assessment: The case for Web-based teaching programs. Australia Journal of Educational Technology, 13(1), 23-39. http: / / www.ascilite.org.au/ajet/ajet13/ freeman.html

Fry, P. \& Coe, K. (1980). Interactions among dimensions of academic motivation and classroom social climate: A study of the perceptions of junior high and high school students. British Journal of Educational Psychology, 50, 33-42.

Herrington, J. \& Oliver, R. (1998). Using situated learning and multimedia to promote higher-order thinking Ottmann, T. \& Tomek, I. (Eds). Proceedings of Proceedings of Ed-Media/Ed-Telecom 98 World Conference On Educational Multimedia And Hypermedia \& World Conference On Educational Telecommunications. Virginia: AACE. (pp 565-570).

Herrington, J. \& Oliver, R.(1997). Avenues to understanding: A qualitative study into how students learn from multimedia. In T. Muldner \& T. Reeves, (Eds.), Educational Multimedia/Hypermedia and Telecommunications 1997, (pp 473-478). Charlottesville, VA: AACE.

Hoyles, C., Healy, L. \& Pozzi, S. (1992). Interdependence and autonomy: Aspects of groupwork with computers. Learning and Instruction, 2, 239-257.

Hoyles, C., Healy, L. \& Pozzi, S. (1994). Groupwork with computers: An overview of findings. Journal of Computer Assisted Instruction, 10, 202-215.

Johnson, D., Johnson, R. \& Stanne, M. (1986). Comparison of computer-assisted cooperative, competitive and individualistic learning. American Educational Research Journal, 23(3), 382-392.

Jonassen, D. (1991). Thinking technology: Context is everything. Educational Technology, 31(6), 35-37.

Laurillard, D. (1993). Rethinking university teaching: A framework for the effective use of educational technology. London: Routledge. 
Light, P. (1993). Collaborative Learning with computers. In Language, Classrooms and Computers (ed. P. Scrimshaw). London, Routledge.

McManus, T. (1995). Special considerations for designing Internet-based education. In (D. Willis, B. Robin \& J. Willis (Eds.) Technology and Teacher Educationa Annual. Charlottesville: AACE.

Masterton, S. (1998). Computer support for learners using intelligent educational agents: the way forward. In Chan, T., Collins, A. \& Lin, J. (Eds). Global Education on the Net: Proceedings of the 6th International Conference on Computers in Education. China Higher Education Press Beijing and Springer Verlag, Heidelberg. (pp 211-219).

Mayes, J. \& Neilson, I. (1995). Learning from other people's dialogues: Questions about computer based answers, In B. Collis \& C. Davies (Eds). Innovative Adult Learning with Innovative Technologies. North Holland: Elsevier Science.

Parker, A. (1997). A distance education how-to manual: Recommendations from the field. Educational Technology Review, 8, 7-10.

Prawat, R. (1993). The value of ideas: Problems versus possibilities in learning. Educational Researcher, August-September, 5-16.

Ramsden, P. (1992). Learning to teaching in higher education. London: Routledge.

Sage, S., \& Torp, L. (1997). What does it take to become a teacher of problem-based learning? Journal of Staff Development, 18, 32-36.

Slavin, R. (1977). Classroom reward structure: An analytical and practical review. Review of Educational Research, 47(4), 633-650.

Vernon, D. (1995). Attitudes and opinions of faculty tutors about problem-based learning. Medical Education, 23, 542-558.

Dr Ron Oliver

Associate Professor

Coordinator of Interactive Multimedia

School of Communications and Multimedia

Edith Cowan University

Mt Lawley 6050 Western Australia

r.oliver@cowan.edu.au 